\title{
Medline indexing success and future directions for Irish Journal of Psychological Medicine
}

\author{
John Lyne* \\ Royal College of Surgeons in Ireland and North Dublin Mental Health Services, Ashlin Centre, Beaumont Road, Dublin 9, Ireland
}

\begin{abstract}
Irish Journal of Psychological Medicine (IJPM) was recently accepted for indexing on Medline. This reflects the high scientific quality of articles published in the journal and highlights the excellent work by publishers, authors, reviewers and the journal editorial board who have contributed to the journal's development over many years. IJPM remains committed to further progression through constant innovation and maintaining the excellent standard of publishing to date. We look forward to promoting our aims of improving knowledge and advocating for better mental health services by continuing to highlight key topics of current relevance to mental health.
\end{abstract}

Key words: Indexing, Journal, Medline, Publishing.

\section{Medline indexing}

The entire team working at Irish Journal of Psychological Medicine (IJPM) is delighted to announce that it was recently accepted for indexing on Medline, the largest and most prestigious biomedical bibliographic database worldwide. The successful Medline indexing application is a reflection of the high academic standard demonstrated by submitting authors and article reviewers. The Editorial board have worked intensively to improve the quality of the journal and make it more relevant for readers. Editorial input from Irish academic leaders has ensured that excellent standards of publication have been maintained over many years. Editorial input by international academics, some of whom are recognised as international leaders and innovators in mental health, has helped IJPM to develop into a journal worthy of international recognition.

The National Library of Medicine grants Medline indexing following an application to the Literature Selection Technical Review Committee (LSTRC). LSTRC convenes three times per year and examines approximately 180 journals at each meeting, recommending $12-15 \%$ of considered journals for indexing (U.S National Library of Medicine, 2018). The successful Medline indexing application will convey several benefits for IJPM such as the improved online visibility of the journal both internationally and for mental health researchers in Ireland. Another benefit is the availability of Medline Medical Subject Headings (MeSH) for articles in IJPM, which is important for allowing

\footnotetext{
* Address for correspondence: John Lyne, Royal College of Surgeons in Ireland and North Dublin Mental Health Services, Ashlin Centre, Beaumont Road, Dublin 9, Ireland.

(Email: johnlyne@mail.com)
}

articles to be found using specific searches, increasing the likelihood that IJPM articles will be found by researchers globally.

\section{Development of IJPM}

Medline indexing is reserved for journals achieving a high standard of academic publishing, a feat which was achieved with stepwise progression by IJPM over many years (Kelly, 2010). IJPM is the oldest journal in Ireland dedicated to publishing on mental health, founded by Dr Mark Hartmann in 1982. Dr Hartmann worked tirelessly to foster the early development of the journal, and progression was steadfastly continued by subsequent Editors, Prof. Brian Lawlor and Prof. Brendan Kelly. Journal advancement included providing an environment for high-quality publishing by appointing a highly respected editorial board with a broad base of academic expertise. The introduction of online formatting for the journal and collaboration with other organisations were also key milestones in the journal development.

Cambridge University Press (CUP), the oldest publishing house in the world, partnered with IJPM in 2013 elevating the journal to new heights by ensuring much improved journal usage and distribution. Working with CUP has increased international readership through distribution of the journal to a wide geographic audience across all continents, including through philanthropic aid/donation schemes for low- and middleincome countries. Over $99 \%$ of institutions with access to the journal are outside of Ireland (86\% outside Europe) and the journal is regularly promoted at international conferences. Article downloads in 2017 occurred in 110 different countries, with $86 \%$ of downloads outside of Ireland. Between 2016 and 2017 article 
downloads increased by $134 \%$, with over 22,000 fulltext downloads in 2017; the United States had the most downloads with over 8,000 . These statistics reflect the increasing international relevance of the journal, and the recently launched CUP online platform (Cambridge Core) has further improved the journal interface and reader experience.

Another development for the journal has been the appointment of an international advisory board with the purpose of advocating for the journal internationally and ensuring that the journal adheres to international standards of publishing. The journal has increased its online and social media presence by appointing a Social Media Editor in 2017, another essential step for increasing influence and dissemination of journal content to a wider audience. A recently added twitter account (@IrishJournPsych) has been successful in receiving over 6,000 impressions for some tweets.

Another major stride forward for IJPM was partnering with the College of Psychiatrists of Ireland in 2012, thereby ensuring the longer term stability of the journal. Partnering with a professional medical body has resulted in better governance structures within the journal, and the role of the College of Psychiatrists of Ireland in educating psychiatrists through the promotion of research is a shared goal with the journal. It is to be hoped that Medline indexing for IJPM will improve mental health research in Ireland, as well as providing a platform for internationally renowned academics to engage with Irish clinicians and researchers.

\section{Future directions}

IJPM has established itself as a journal with a tradition of publishing high-quality research on a broad range of mental health topics appropriate for clinicians, researchers and policymakers. Current strengths of the journal include a focus on clinically relevant contemporary issues with regular special themed issues guest edited by internationally respected academic experts highlighting important issues. There are currently several special themed issues in development and the journal will continue to publish important and relevant research in this manner.

By reaching a wider audience IJPM can act as a forum for positive change in how mental health services are delivered. The journal also aims to report research that is evidence-based and which may impact on clinical care. The Editorial board look forward to developing the journal further through constant innovation with the needs of IJPM readers in mind. We look forward to continued publication of research with high scientific merit while striving towards our aims of advocating for improved outcomes and better mental health services for all.

\section{Conflict of Interest}

John Lyne has no conflicts of interest to disclose.

\section{Ethical Standards}

The author asserts that all procedures contributing to this work comply with the ethical standards of the relevant national and institutional committee on human experimentation with the Helsinki Declaration of 1975 , as revised in 2008 .

\section{Financial Support}

This research received no specific grant from any funding agency, commercial or not-for-profit sectors.

\section{References}

Kelly B (2010). The Irish Journal of Psychological Medicine: looking to the future. Irish Journal of Psychological Medicine 27, 170-171.

U.S. National Library of Medicine. FAQ: Journal selection for Medline indexing at NLM (https:/ / www.nlm.nih.gov/ lstrc/j_sel_faq.html). Accessed September 26th 2018. 